\title{
Popigai, Siberia—well preserved giant impact structure, national treasury, and world's geological heritage
}

\author{
1 Institut für Planetologie, Westfälische Wilhelms-Universität Münster, Wilhelm-Klemm-Str. 10, D-48149 Münster, Germany; \\ e-mail: deutsca@uni-muenster.de \\ 2 Karpinsky Geological Institute, Sredny prospekt 74, St. Petersburg, 199106 Russia; e-mail: vsegei@mail.wplus.net.ru \\ 3 Bayerisches Geoinstitut, Universität Bayreuth, D-95440 Bayreuth, Germany; e-mail: Falko.Langenhorst@Uni-Bayreuth.DE \\ 4 Earth Sciences Sector, 601 Booth Street, Ottawa, Ontario K1A 0E8, Canada; e-mail: rgrieve@gsc.nrcan.gc.ca
}

\begin{abstract}
The about 35-Ma old Popigai impact structure is located on the northern edge of the Anbar shield in subpolar Siberia. Among the terrestrial "impact ring basins", the $100 \mathrm{~km}$ diameter Popigai represents the best preserved example with excellent outcrops. In addition, a large number of drill holes and geophysical surveys helped to constrain the sub-surface nature of the crater, making Popigai a three-dimensional model for similar impact structures on other terrestrial planetary bodies. Moreover, this crater is the type locality for impact diamonds surpassing there in their total mass that at all other known diamond deposits together; alone this fact makes Popigai a national treasury. The structure which is most probably linked to ejecta horizons occurring in marine sequences of Late Eocene age, has been designated by UNESCO authorities as part of the world's geological heritage. Due to economic reasons, exploration work in this quite remotely area has ceased more than a decade ago, making new field studies in this crater virtually impossible. We outline the basic characteristics of this world-class site for impact research, the history of discovery and mineral exploration, and report on IPEX 1997, the first International scientific Popigai Expedition.
\end{abstract}

\section{Impact, a process that shapes planetary surfaces}

Impact is an ubiquitous process in our solar system. Impacts were the driving force in the accretion of planetesimals, and the Moon originated most probably by the hypervelocity impact of a Mars-sized object with the proto-Earth (for a review see, Cameron, 1997). The surfaces of all solid bodies in the solar system, except Io, the Earth, and Venus, are entirely, or to a great degree, shaped by the scars of hypervelocity projectiles of all sizes (Greely, 1994). These impacts resulted in the formation of craters with ejection of material beyond the crater rim. Ejection due to impact has caused material to be expelled from the gravity field of planets (Melosh, 1984), as demonstrated by the presence of lunar (Bischoff and Stöffler, 1992) and Martian meteorites (McSween, 1994). During the highly violent and transient impact process, large amounts of kinetic energy, delivered by the projectile, are transferred to the target, causing unique disequilibrium changes in rocks and minerals, including whole rock melting and vaporization (Melosh, 1989). This short-time process is referred to as impact metamorphism.

The significance of cratering for the evolution of planet Earth is still a matter of debate, although planetary exploration, and modern research on meteorites have yielded wide-spread evidence for the general significance of impact processes. Earth was regarded for a long time as a specific, "shielded" environment, not as a cosmic body, similar to other planets. Evidence for the importance of hypervelocity impacts for the Earth was produced only in 1980, when the concept of an impact-induced crisis was introduced to explain the long-known extinction at the Cretaceous-Tertiary $(\mathrm{K} / \mathrm{T})$ boundary, 65 Ma ago (Alvarez et al., 1980; Smit \& Hertogen, 1980). Ten years later, the ${ }^{\prime} 190 \mathrm{~km}$ sized Chicxulub impact structure was identified as "smoking gun" for the K/T event, buried under a km thick blanket of post-impact sediments in Yucatan, Mexico (e.g., Morgan et al., 1997). In July 1994, we witnessed the impact of comet ShoemakerLevi 9 on planet Jupiter. This spectacular event and the K/T story have convinced the geoscientific community as well as laymen on the role of impacting extraterrestrial projectiles for the evolution of the atmosphere and life. Moreover, extraterrestrial bolides represent a continuous danger for civilization (Gehrels, 1994).

The currently known number of terrestrial impact structures (about 160) and ejecta horizons in the sedimentary record (about 20) still represents only a sub-set of the totally expected traces of impact events (Grieve, 1998; Grieve and Pesonen, 1996). These known structures, ranging in diameter up to $300 \mathrm{~km}$, are up to 2.02 billion years old, and are found preferentially on stable shield areas with low time-integrated erosion rates. Investigation of impacts structures which vary in morphology from the small, simple, bowl-shaped craters such as the Barringer Crater (Arizona; e.g., Roddy et al., 1975 ) to the large complex structures with rings, annular troughs, and central uplifts, is not only of interest in the normal geological context, but has also a planetary dimension: the 3D access to well preserved impact structures is mandatory for a better understanding of the cratering process on Earth and other planetary bodies. Popigai in Russia (N 71 $28^{\prime}$ E $110^{\circ} 11^{\prime}$; Figure 1), fulfills all aspects for an ideal crater model. It is a large, nearly uneroded complex impact structure which has been extensively drilled. The only setback is that Popigai is situated in a very remote, sub-polar part of Siberia, inhabited only by a small group of the Dolgan tribe. 


\section{On the discovery and exploration of the Popigai structure}

At the end of the 40's, geological teams started to investigate the northern part of the Siberian platform, where they discovered a circular depression in the relief, about $70 \mathrm{~km}$ across (Figures 1, 2). For decades, the origin of this strange geological feature was ascribed to erosion, or tectonic subsidence, or a combination of these processes with volcanic eruptions that occurred in East Siberia in Permian and Early Triassic times, about of 250 million years ago. Interestingly, some geologists have already noted in the late 50's similarities between these volcanic processes which were assumed to have produced the Popigai depression, and that one causing formation of the Ries Kessel in Germany. At that time, the most popular scientific interpretation of the Ries (impact) crater was either an origin as ancient volcanic caldera or that it represent the site of a "cryptoexplosion". The so-called volcanics at the Popigai site differ at the first glance from true basaltic to andesitic rocks by an extremely high abundance of inclusions ranging in size from rock fragments, tens of meters across, down to millimeter-sized mineral clasts (Figure 3). Despite these strange characteristics, the remarkable Popigai rocks and the frequent occurrence of breccias at this isolated place did not attract scientific attention. Nobody tried to explain the numerous enigmatic features at Popigai which include, for example, the occurrence of ancient crystalline basement rocks on the surface inside the circular depression.

Space exploration, and finally, the period of intense lunar research brought craterform-structures and the origin of breccias deposits and strange "volcanics" into scientific focus. The impact origin of lunar craters was substantiated, and the features diagnostic for shock metamorphism were established. As a consequence, geologists discovered in Europe and North America numerous sites of ancient cosmic catastrophes caused by the impact of asteriodal or cometary bodies.

With this background, the Popigai enigma was approached again. Geological studies, and especially petrographic observations on the various breccias yielded a new, and totally different picture of the structure. It was considered for the first time as an impact crater, about 40 Ma old (Masaitis et al., 1975). Contemporaneously, the "volcanics" were recognized as impact melt rocks, and later as the host rocks for a quite specific class of diamonds, which had been previously found in placers close to the impact structure. Popigai turned out to be the first terrestrial location containing "impact diamonds" (Masaitis et al., 1972). The discovery of this high pressure carbon polymorph in Popigai impact rocks initiated in the 70-80's largescale exploration programs, including geophysical surveys, and extensive drilling. Exploration work revealed not only Popigai as tremendously rich deposit of impact diamonds (Masaitis, 1998), but unveiled the sub-surface structure of the crater, as well as the composition and distribution of impact-related rock formations (Masaitis et al., 1975; 1998). Popigai was shown to represent an extremely well preserved complex structure (Masaitis et al., 1998), forming a three-dimensional textbook for the geology of large complex impact craters, and an ideal object for general studies on the cratering process.

\section{A roundtrip over the crater}

As illustrated in Figure 1, the Popigai structure is significantly imprinted on the flat or slightly rippled landscape of northern Siberia. Several arcuate chains of steep hills enhance the concentric structure of the crater. Transportation by helicopter is the only way for geological teams such as our International Popigai Expedition (IPEX 1997) to reach this remote place. During the flight from Khatanga to Popigai, the monotonous tundra, covered by debris of light-colored limestone and dolomite, dominates the vista. Suddenly the landscape changes to swampy areas spotted with numerous lakes; brownish table-shaped uplands and hills appear, and steep, dark-colored cliffs form prominent landmarks. The drainage system -blue rivers with light-yellow gravel and sandy beaches-mirrors the concentric structural features of the crater area. Along the valleys, groves of low larch trees and bushes of dwarf birches occur. About $30 \mathrm{~km}$ upstream of the estuary of the Rassokha in the Popigai river, there are breath-taking outcrops of the rock series which fill the crater (Figure 4). The up-to-150 m high rocky slopes continue for about $10 \mathrm{~km}$, and similar outcrops occur along the tributaries of the Rassokha river for additional 10 to $15 \mathrm{~km}$ southward and northward. The helicopter of the IPEX 1997 team landed on the riverbank opposite to such a huge cliff, which displays a broad spectrum of variously colored rocks that are mixed together in a seemingly quite chaotic arrangement (Figure 5). In the light of the lowering sun, this cliff resembles a giant mural.

This apparent chaos originated in the cratering process, and represents an allogenic or allochthonous polymict breccia. The spectrum of the clasts reflects the geological situation at the impact site, $35 \mathrm{Ma}$ ago. The rocks range from dark brown and grey Archean gneiss; black diabase and pinkish quartzites of Proterozoic age; light-green, yellow and dark red Cambrian claystone, white and light brown limestone and dolomite of the same age, banded Permian sandstones of grey color, over bluish Jurassic clays to black fragments of Cretaceous coal. Here and there bombs or shards of dark green vesicular impact melt glass occur, as well as black dykes of injected impact debris (Figure 6). This giant accumulation of variously crushed and mixed rocks is cemented by a greyish, sandy matrix which, in turn, includes abundant small angular fragments of the already mentioned rock types, impressive impact-melt coated "gneiss bombs" (Figures 7, 8), and a few shards and particles of partly weathered impact glass. This polymict breccia is a typical impact formation, occurring in similar form at other terrestrial craters such as the Ries (von Engelhardt et al., 1995), Haughton (Canada; e.g., Grieve, 1988), or Sudbury (Canada; e.g., Deutsch et al., 1995). Polymict impact breccias have been identified in the lunar sample collection, as well as amongst meteorites.

At Popigai, the polymict breccia is capped by the erosional remnant of a sheet of chilled impact melt rocks. These so-called tagamites are named after the Tagamy ridge at Popigai. The tagamites form for several km along the Rassokha riverbed a spectacular brown wall with abundant, irregularly dispersed white patches-inclusions of rock fragments (Figures 3,4). Most of the inclusions in the melt sheet are brecciated and shocked gneiss clasts. The largest ones, up to $20 \mathrm{~m}$ across, are concentrated at the base of the sheet yet all parts of the tagamite layer carry abundant rock and lithic fragments down to a size of $1 \mathrm{~mm}$. At dawn, the melt sheet appears as impressive dark wall, explaining the native name Khara Khaia or "Black Mountain" (Figure 9).

During IPEX 1997, the huge tagamite outcrops were systematically sampled. In addition, the footprints of our team reached out to distances up to $20 \mathrm{~km}$ away from the camp site, leaving imprints on the forest' moss, on the swampy creek terraces, and on the sand of the Rassokha river banks. Sometimes the footprints crossed those of the wolves (Figure 10), which usually migrate in this season to the north along with herds of wild northern deers. Deer horns are frequently found whereas remnants of more exotic former inhabitants of the Popigai region are only detected with luck. Occasionally, a heavy, up to four meter long mammoth tusk is found on the river terraces. Not far from our camp, Russian colleagues in our team discovered a mammoth skull, which was washed out from recent river deposits (Figure 11) during a flood caused by three days of heavy raining.

In general, this north-western sector of the Popigai crater forms to the outer edge of the annular trough, which is filled with allogenic breccia and melt rocks (Figure 2). These impact formations are widely distributed within the crater depression but thin out, and finally disappear at the crater's edge. Further outwards, parauthochthonous sediments form an up to $15 \mathrm{~km}$ wide ring zone, which display numerous upthrusts, irregular folds and other disloca- 

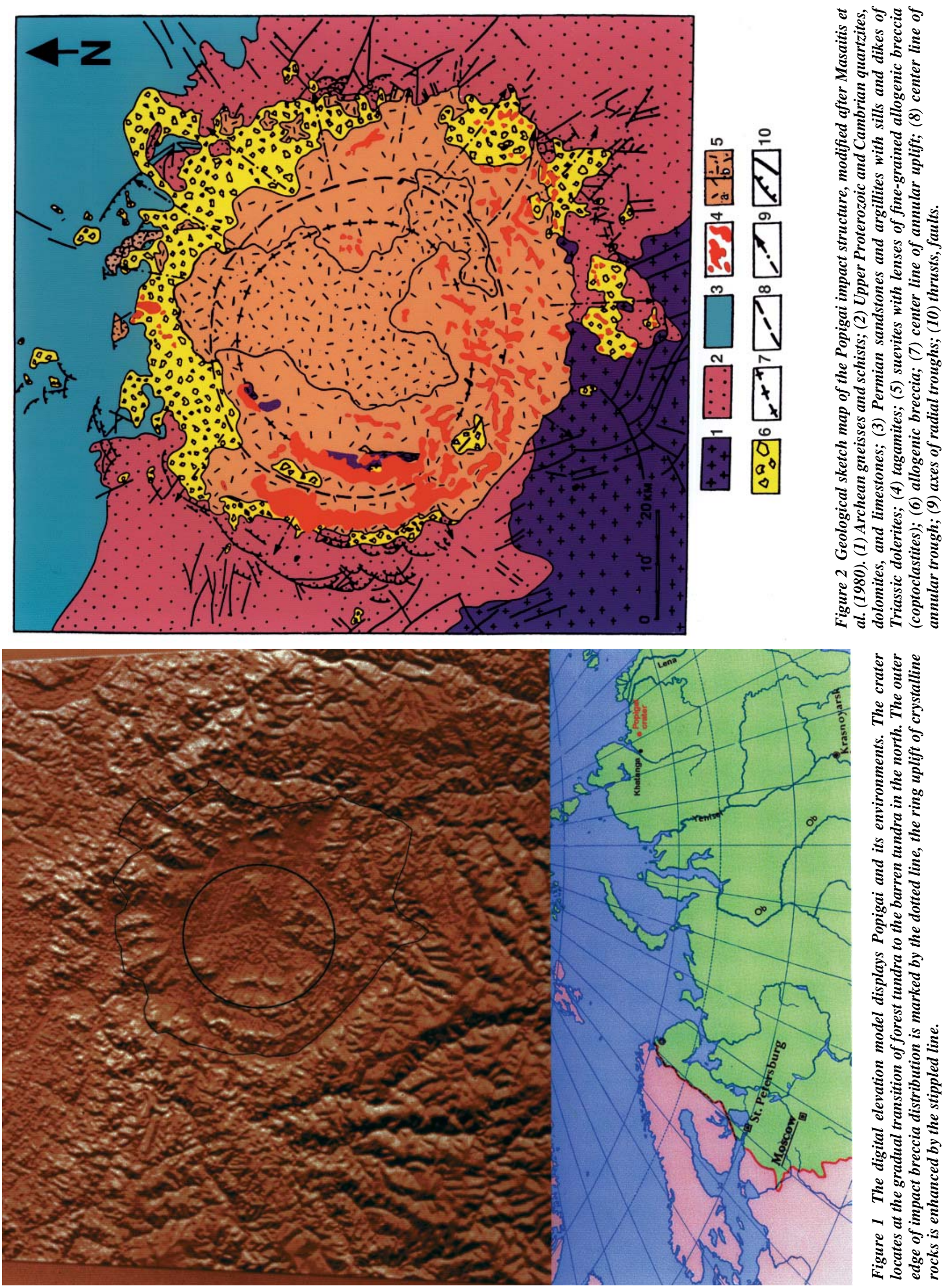

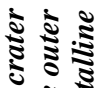
ะี จ 年 . ริ $\approx \Sigma$ $\Xi \Xi$ ㄴํำ ล워 จ ลิำ 온 बิ ฐ. ริ) ถู่ ป ฐ) $\approx$ ㅇำ ริ $-\frac{3}{3}$ : \% : เป็ 
tions; all these features attenuate outward. Up to a distance of $70 \mathrm{~km}$ from the crater center, small patches of allogenic breccia occur as remnants of the once coherent ejecta blanket.

According to geological mapping and drilling, the inner part of the crater consists of an about 1-2 km deep annular through that surrounds, in turn, the ring uplift of brecciated and shocked crystalline rocks (Figures 1,2). The central depression inside this annular uplift is partly buried under a thick sequence of predominantly fine grained fall-back breccias and impactites. As shallow drilling failed to reach the bottom of the central depression, the thickness of the crater fill is estimated to reach $2.5 \mathrm{~km}$. Geophysical data indicate the presence of a small, flat central uplift in the crater center, consisting of brecciated and partly melted crystalline rocks. According to this complex geological situation, the Popigai crater represent a smaller terrestrial analogue for the large multi-ring impact basins on the surfaces of other planets. Hence, Popigai exhibits an unique terrestrial geological feature, as the only other known terrestrial multi-ring structures are either eroded (Vredefort, South Africa, Therriault et al., 1997), tectonized and eroded (Sudbury; Deutsch and Grieve, 1994), or buried under a km thick post-impact sedimentary sequence (Chicxulub; Morgan et al., 1997).

\section{Rocks and minerals record the impact event}

As mentioned, the rocks of the crater fill and the relics of the ejecta blanket outside the crater have undergone in the time span of seconds to minutes, a succession of processes that lack analogies with other geologic environments (Melosh, 1989). This so-called impact metamorphism is characterized by high dynamic pressures and high temperatures (Figure 12), and involves shock compression, followed by unloading, material displacement, and in certain cases, ejection of material. On the scale of rocks, impact results in the crushing of rocks and mixing of the various fragments into "polymict impact breccias", or generate totally new rocks. Amongst those, "impact melt lithologies", which originate due to the residual heat after pres- sure decay, are most characteristic. Dynamic pressures in excess to about $50 \mathrm{GPa}$ are necessary for shock melting, yet this limit depends on lithology, as well as on porosity, and water content of the rocks. Turbulent mixing of the shock melted material yields fairly homogeneous compositions; during the movement of this superheated mass, numerous clasts of all sizes are included. A part of the impact melt is ejected and now forms bombs and shards in breccias of the crater infill and in the ejecta blanket. This mixture of shocked and unshocked rock fragments and impact melt is called suevite (or suevitic breccia). Large volumes of rocks at Popigai consist of suevites. A significant volume of the impact melt stays inside the crater and forms the coherent melt (tagamite) bodies. The total volume of solidified impact melt in the Popigai crater is estimated to exceed $1800 \mathrm{~km}^{3}$ (Masaitis, 1994). On Earth, only the Sudbury impact structure contains a preserved higher amount of impact melt rocks.

Some of the Popigai melt rocks contain a contamination by projectile material (Masaitis and Raikhlin, 1986), which was vaporized during the collision and, hence, ceased to exist: Evidence for this socalled meteoritic component is provided by unusual high abundance of elements, such as nickel or iridium, which have high concentrations in some types of impactors relative to the Earth's crust. A repetition of these earlier studies, however, is required with better suited samples and more sophisticated analytical techniques, in order to finally constrain the type of projectile which punched this large hole in the crust of Siberia. For this purpose, the whole spectrum of melt rocks was carefully sampled during IPEX 97.

Table 1 summarizes the typical shock features on the scale of minerals (Langenhorst and Deutsch, 1998; French, 1998, Grieve et al., 1996), ranging with increasing pressure and temperature, and therefore, post-shock temperature, from the formation of crystal defects through the formation of high-pressure polymorphs to melting, and finally vaporization. In the context of shock metamorphism, the threshold pressure for the martensitic transformation of graphite to diamond is $35 \mathrm{GPa}$ (Figure 13). All these short-time processes are unique. They occur in nature only in the context of impact processes, and they are irreversibly due to the deposition of high amounts of internal energy in the target material. Some of these deformations and transformations of rock forming minerals are diagnostic for shock events, and can not occur in other fields of dynamic crustal

Table 1 Typical shock effects in minerals, modified after Langenhorst and Deutsch (1998).

\begin{tabular}{|c|c|}
\hline EFFECTS & SHORT DEFINITION \\
\hline $\begin{array}{l}\text { (1) formation of crystal defects } \\
\text { (a) dislocations } \\
\text { (b) planar microstructures } \\
\text { - planar fractures } \\
\text { - planar deformation features } \\
\text { (c) mechanical twins } \\
\text { (d) kink bands } \\
\text { (e) mosaicism }\end{array}$ & $\begin{array}{l}\text { linear lattice defect } \\
\text { crystallographically oriented cleavage planes activated } \\
\text { under dynamic compression } \\
\text { crystallographically oriented sets of amorphous lamellae } \\
\text { (undecorated PDFs) and their post-shock modifications } \\
\text { (decorated PDFs) } \\
\text { crystal domains related by a point symmetry element (mir- } \\
\text { ror, rotation or inversion axis) and produced by defor- } \\
\text { mation } \\
\text { externally rotated crystal domains without crystallographic } \\
\text { relationship to the host } \\
\text { lattice, produced by deformation internal blocky structure } \\
\text { of shocked crystals }\end{array}$ \\
\hline $\begin{array}{l}\text { (2) transformations to } \\
\text { (a) high-pressure polymorphs } \\
\text { (b) diaplectic glass }\end{array}$ & $\begin{array}{l}\text { densely packed modifications of minerals } \\
\text { quenched high-pressure melt preserving shape and internal } \\
\text { textures of the precursor crystal }\end{array}$ \\
\hline (3) decomposition & $\begin{array}{l}\text { dissociation of minerals into new solid phases (and } \\
\text { gaseous species) }\end{array}$ \\
\hline (4) melting and vaporisation & production of rock and mineral melt, and vapor \\
\hline
\end{tabular}

In general, pressure, shock-, and post-shock temperature required for formation of the effects increase from (1) to (4). 


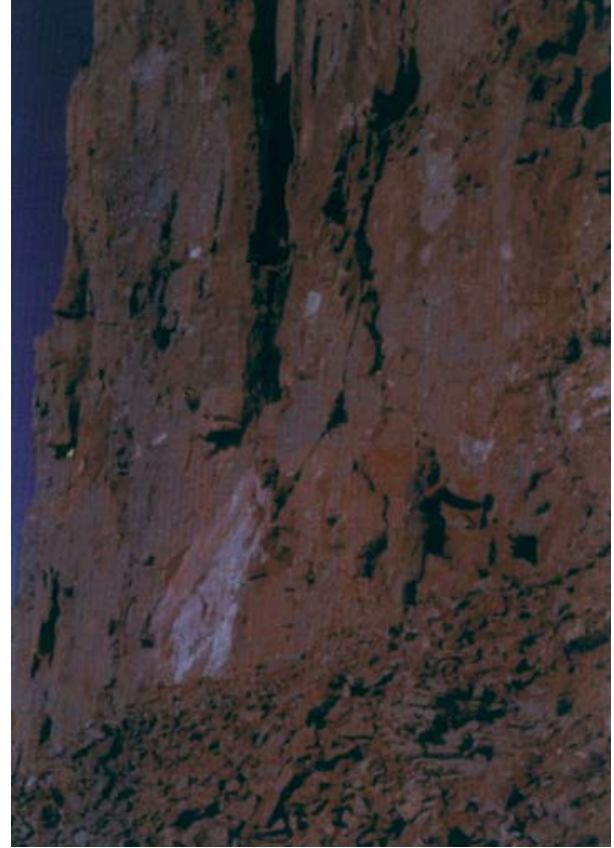

Figure 3 A vertical cliff that consists of impact melt rocks (tagamites) engulfing blocks of Archean gneiss from the basement (bright patches). This material has been considered for a long time as volcanics.

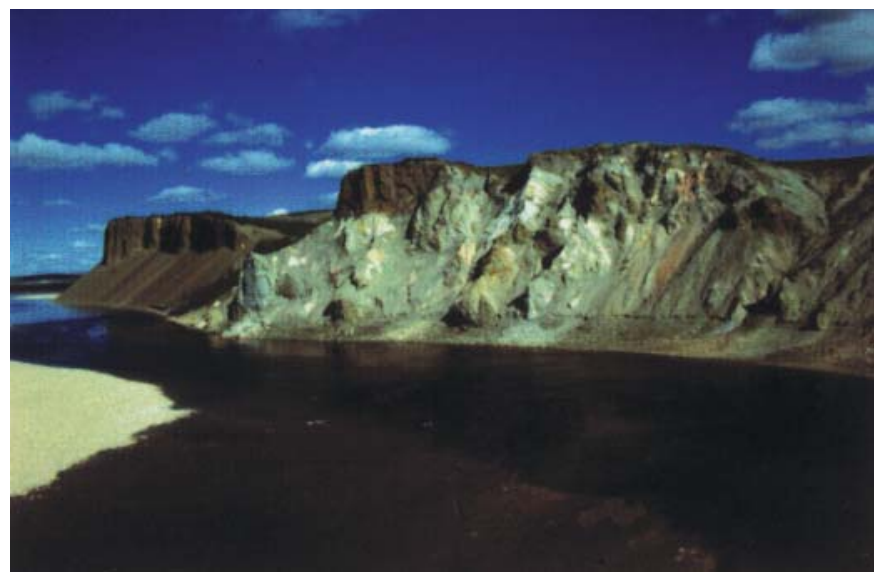

Figure 4 Impact melt rocks on top of the polymict allogenic breccia form up to $140 \mathrm{~m}$ height cliffs along the eastern shore of Rassokha river.

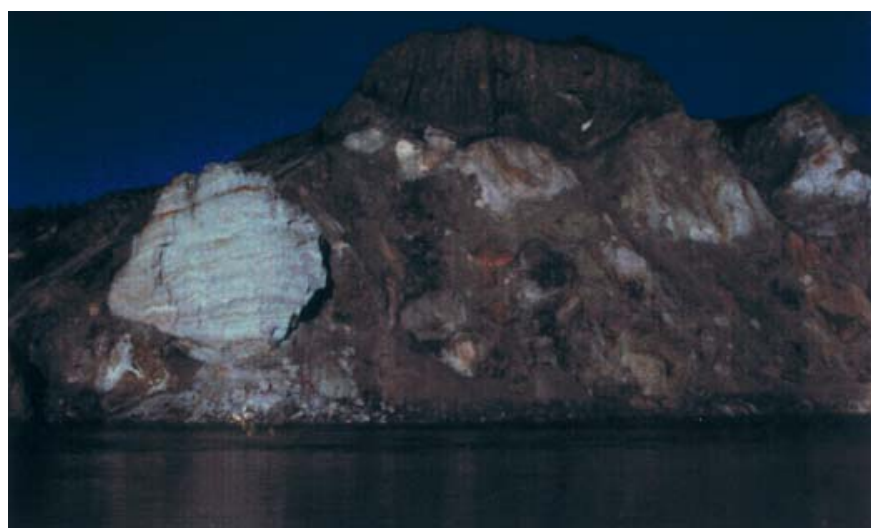

Figure 5 Huge gneiss blocks shocked to various degrees, dominate the clast freight of the polymict breccia that is exposed on the eastern shore of Rassokha river. The cap of tagamites displays columnar fissures. glass.

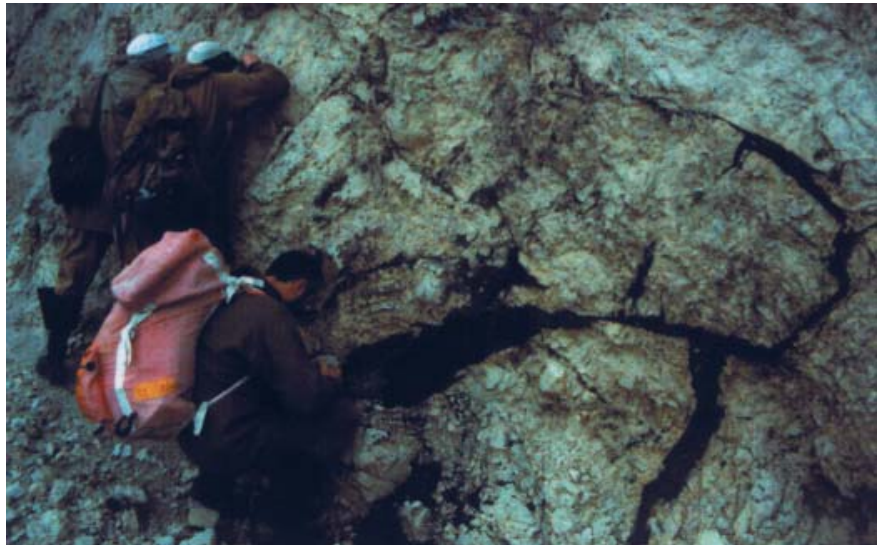

Figure 6 Veins and pockets of black impact debris in a gneiss fragment record the complex, short-time history of shock, injection of impact melt, ejection of the block, and finally deposition in the polymict breccia.

Figure 7 The polymict breccia has a finegrained clastic matrix and carries rounded gneiss bombs which are coated by impact melt
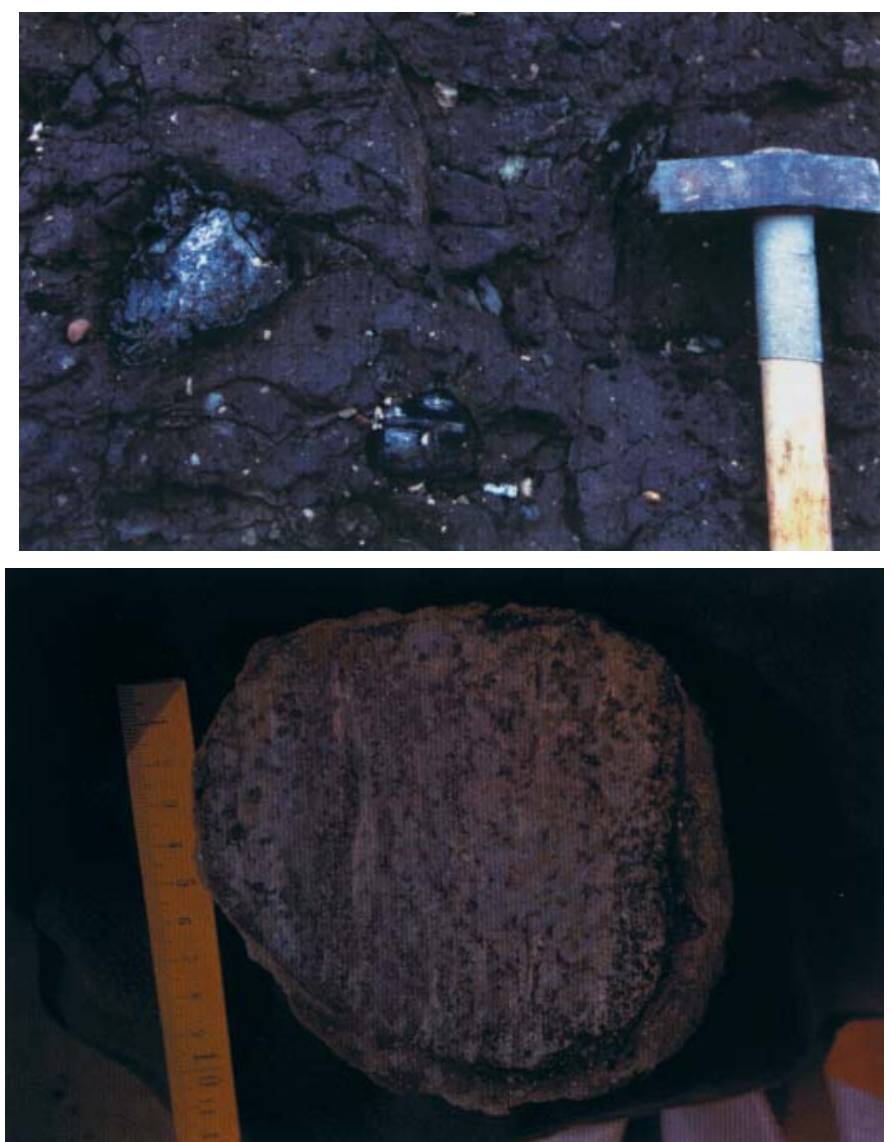

Figure 8 Cut surface of a rounded bomb. The core consisting of garnet gneiss displays a sharp boundary against the coating of black, and green impact melt glass. Note also the small rock and mineral fragments in the coating.

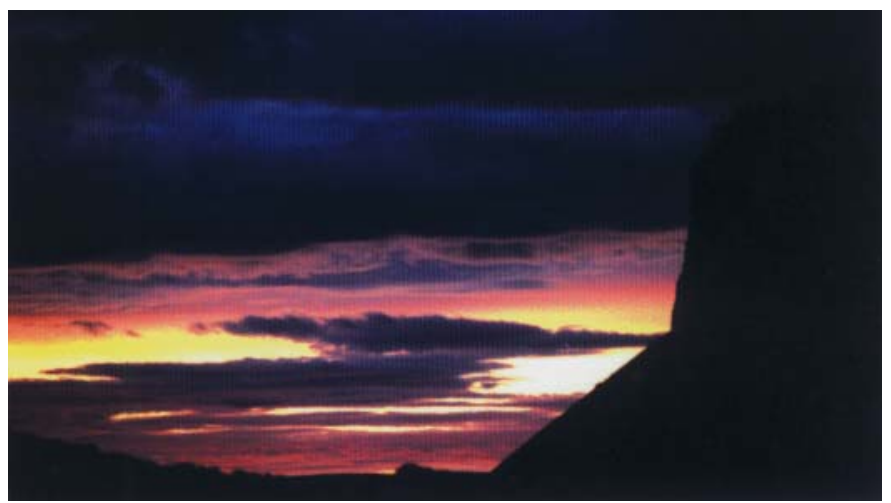

Figure 9 Dawn behind the "Black Mountain". 


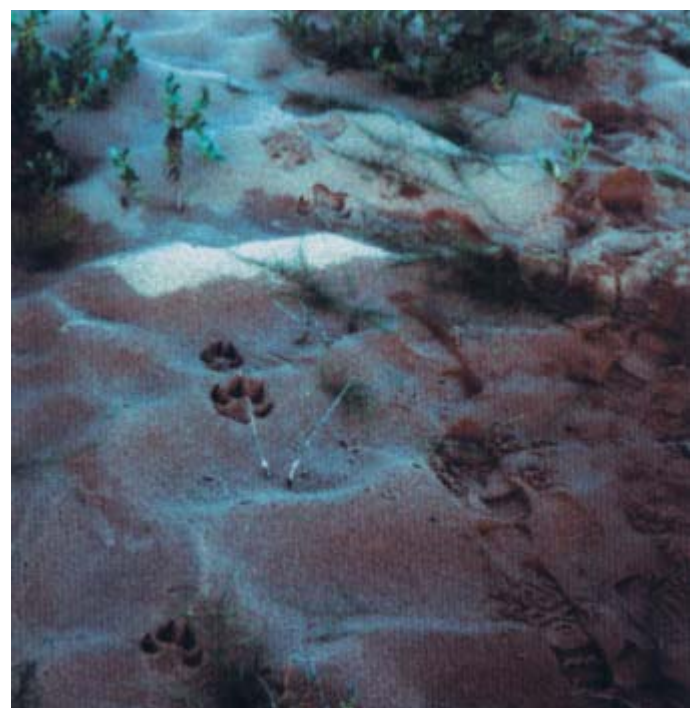

Figure 10 Only the footprints meet each other, not the wolves and the geologists.

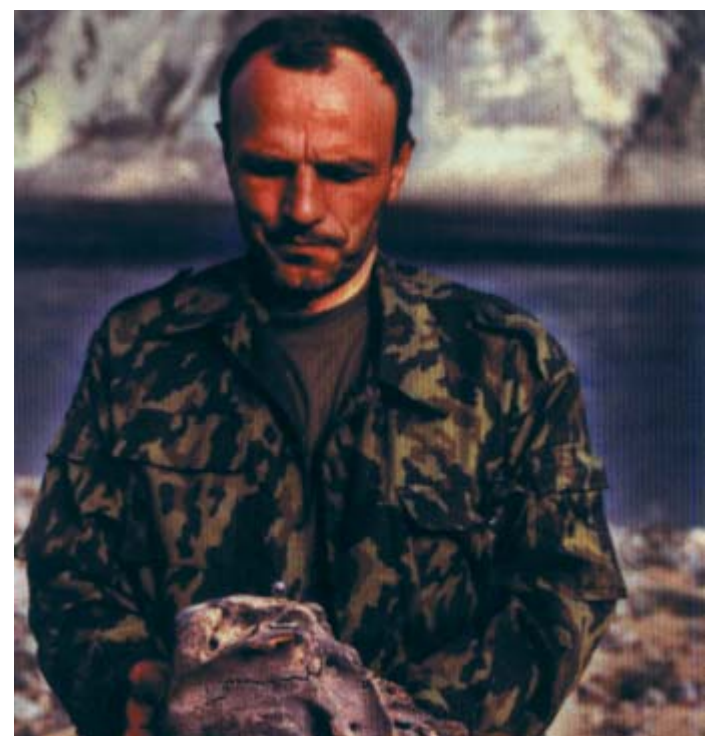

Figure 11 Misha Goncharov holding the cranium of a mammoth baby.

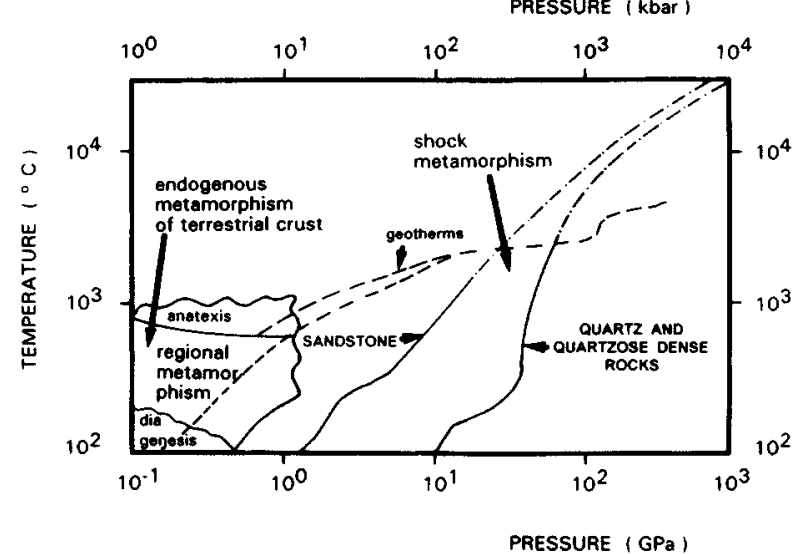

Figure 12 Schematic pressure-temperature diagram outlining the fields of any possible endogenic crustal process (tectonism, plutonism, metamorphism) against shock metamorphism, modified after Stöffler and Langenhorst (1994). A few effects, which are characteristic for shock loading are labeled; they are either related to compression ("shock effects") or post-shock cooling ("post-shock thermal effects").

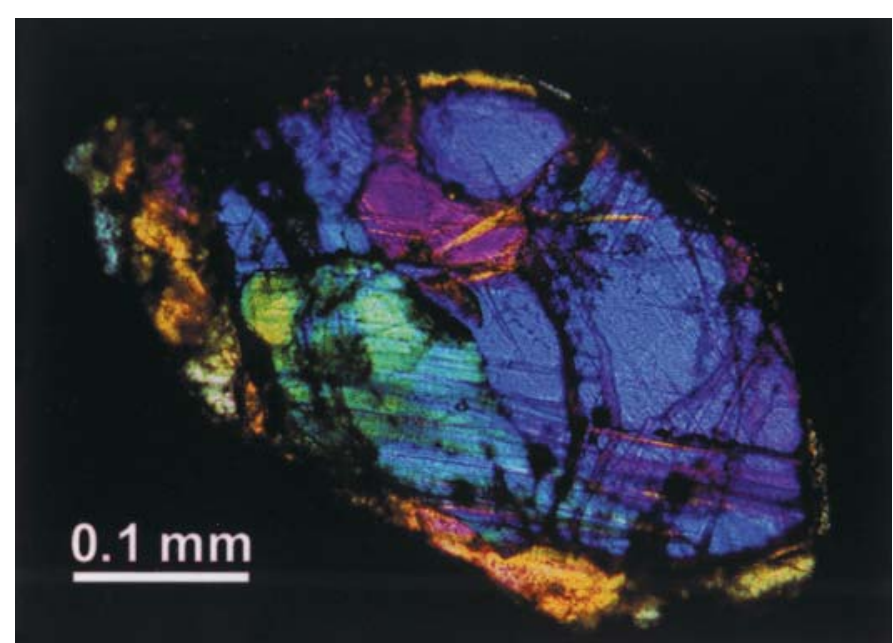

Figure 13 Optical micrograph of a Popigai impact diamond displaying under crossed nicols anomalous birefringence.

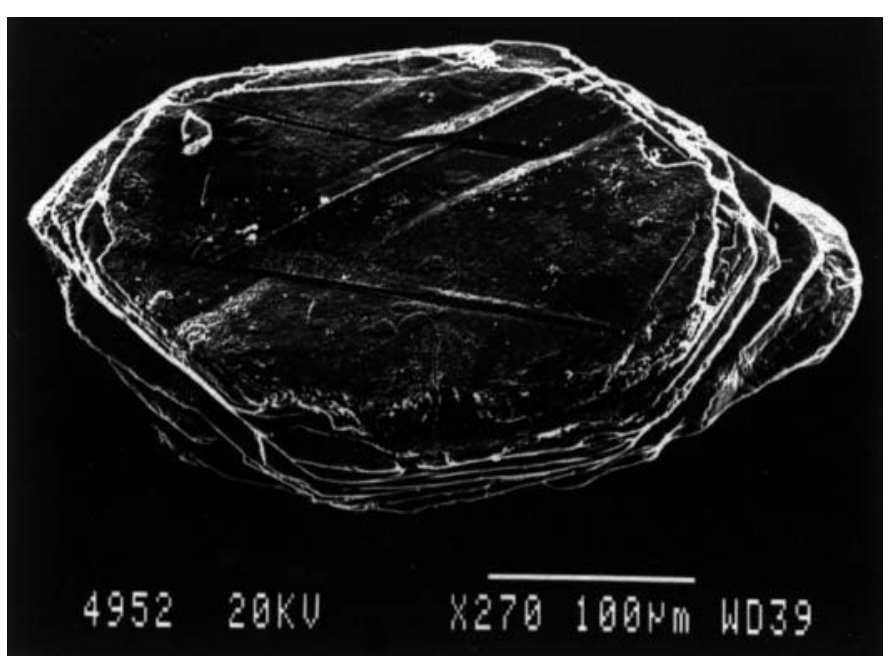

Figure 14 Scanning electron microscopy images of a Popigai impact diamond that has inherited the shape, sheet-like structure and twinning striations on the surface from the precursor graphite.

processes, regardless if these are volcanic, plutonic or metamorphic. The dynamic pressures to produce the characteristic "shock features" (Table 1) have been established in laboratory experiments (e.g., Langenhorst and Deutsch, 1994; Langenhorst, 1994) and confirmed by the study of rock samples from underground nuclear explosions.

As impact lithologies at Popigai are neither weathered nor altered by secondary processes, and because a wide spectrum of differently shocked rocks is present, this impact site offers excellent opportunities to study shock effects at various scales. For example, the gneiss bombs which are coated with impact melt record the whole sequence of processes during cratering from shock, ejection and annealing in the vapor plume above the growing crater, condensation of shock melted material on the bomb's surface till deposition as part of the allogenic breccia (Masaitis and Deutsch, 1999). The participants of IPEX 97 collected beautiful gneiss bombs (Figures 7 , 8 ) in the steep breccia outcrops along the banks of the Rassokha river.

\section{Impact diamonds}

The Popigai crater is the place where at the beginning of the 1970s, impact diamonds have been found for the first time directly in 
shocked and impact-melted rocks (Masaitis et al., 1972; see also paragraph "On the discovery and exploration of the Popigai structure"). Impact diamonds result from martensitic solid-state transformation of graphite, and inherit many properties and characteristics of the precursor graphite (e.g., Masaitis et al., 1990; Masaitis, 1998). That explains why impact diamonds differ from the well-known diamonds in kimberlites. Consequently, early attempts to find similar transparent to translucent kimberlite crystals in Popigai impactites failed. The first diamond grain was discovered occasionally as very hard inclusion in the rock during sawing of samples. After that find, a thorough examination of the Popigai sample collection started to characterize the diamonds and their host rocks. It turned out that the diamonds occur in hard rocks as irregular and tabular grains, and are very rarely colorless, mostly yellow, gray, or black; they never occur in gemstone quality. In some cases, the grains display transparency, strong birefringence and an usually total straight extinction (Figure 13); the latter two properties are not expected to be present for cubic diamond. Popigai diamonds are up to $10 \mathrm{~mm}$ across but their average dimension is $0.5-2 \mathrm{~mm}$. Tabular grains of impact diamonds inherit not only the crystallographic shape of the precursor graphite but also twinning striations on principal faces (Figure 14). The surfaces of some grains display corrosion patterns, including a honeycomb microrelief and lace-like edges. These features show that corroded diamonds have undergone intense heating and oxidation in the host impact melt.

$\mathrm{X}$-ray, SEM and TEM studies revealed that tabular and irregular impact diamonds are polycrystalline aggregates that can contain some remnant and/or secondary graphite. The individual diamond crystallites in the polycrystalline aggregates have a size on the order of 0.1-1 $\mu \mathrm{m}$, and show a distinct preferred orientation. This texture may result from the epitactic relationship of precursor graphite and diamond with $(0001)_{\text {Gra }}$ parallel to (111) Dia. At the lattice scale, impact diamonds display numerous stacking faults and microtwins (Langenhorst, 1997; Masaitis, 1998), a peculiarity that has never been observed in kimberlite diamonds. These unique properties and characteristics as well as their durability make impact diamonds to unequivocal indicators of ancient impact events, even if the crater has already disappeared due to endogenic processes.

Impact diamonds occur as accessories in the ground mass of impact melt rocks (tagamites), and suevites, as well as in lithic clasts of these impactites. At Popigai, the diamond-bearing fragments are garnet-biotite gneisses that have been shock-transformed into a glassy vesicular rock. According to the shock features recorded in the silicate minerals of these rocks, the threshold pressure for the onset of the transformation from graphite to diamond is on the order of 34 to $36 \mathrm{GPa}$. For complete transformation, a minimum pressure of about $60 \mathrm{GPa}$ is estimated.

There are some regularities in the occurrence of diamonds in the impactites within the Popigai crater (Masaitis, 1998). Some radial zones are enriched with diamonds due to heterogeneous distribution of graphite in the target gneisses, superimposed by the concentric zoning of shock metamorphism. The $35 \mathrm{GPa}$ and 60-90 GPa isobars form the boundaries of the concentric zones. The upper pressure limit of $90 \mathrm{GPa}$ results from the fact that high residual temperatures, as typical for larger impact melt bodies, destroy the diamonds by immediate combustion. The primary zoning in the distribution of the shock-induced diamonds was disturbed by the radial ejection of melted material that have a different diamond content. The preservation of diamonds from oxidation and back-transformation into graphite is dependent on the post-shock temperature of the ejected melt material, and its cooling rate after deposition. The super-heated fractions of melt appear to be virtually barren of diamonds after chilling. Placer deposits of impact diamonds adjacent to Popigai originated as result of impactite disintegration and re-deposition. Single grains of impact diamonds were found at a distance of about $100-150 \mathrm{~km}$ from the crater rim indicating that the crystals are relics of totally rewashed distal ejecta.

In terms of energy source and ore formation mechanism, the primary deposits of impact diamonds belong to an absolutely new category of economic resource and are basically different from any sedimentary, magmatic, and metamorphic process, concentrating raw materials in the Earth's crust and on its surface (Grieve and Masaitis, 1994). Impact diamonds have been discovered in other impact structures where graphite-bearing target rocks are present, e.g., Ries, Kara, Puchezh-Katunki, Terny, Zapadnaya, Ilyintsy, Sudbury, and Lappajärvi (Masaitis et al., 1990, 1995, and 1999; Langenhorst et al., 1999). Thus, impact diamonds may be widely distributed, and their occurrence in placers indicates the rewashing of impactites belonging to an either buried or strongly eroded crater close to the impact deposit.

Special investigations and commercial tests showed that the Popigai diamonds occasionally surpass kimberlite diamonds in a number of physical properties, in particular, in their resistance to destruction load. Light-colored impact diamonds are best suited for drills and other abrasive tools. Apographitic impact diamonds represent a new type of industrial diamond raw material, which offers a number of advantages over the well-known types of natural and synthetic diamonds. The economic value of Popigai as deposit for industrial impact diamonds may be significant, taking into account the high abundance of the mineral in several rock types at this impact site, and the very large resources of their host rocks.

\section{Popigai-its present value for planetary science}

The surfaces of most solid planetary bodies are covered, in part even saturated with crater-form structures (e.g., Greely, 1994). A huge amount of data have been obtained for these circular structures during the last decades by remote sensing techniques on the Moon, Mars, Venus, the satellites of the giant gas planets, and on small asteroidal bodies. Various space missions yielded detailed knowledge of morphological parameters but the deep interior of the impact structures as well as composition and type of rocks remained unknown in most cases. It is this fact that underlines the prime importance of a careful 3D study of the terrestrial analogs to the planetary impact structures: Only on Earth, we can collect the basic information necessary to interpret impact features on distant planetary bodies. Multi-disciplinary research on terrestrial impact scars small ones like the bowl-shaped Barringer crater (Roddy et al., 1975), larger ones like the Nördlinger Ries, Germany (e.g., von Engelhardt et al., 1995), or multi-ring structures like Sudbury, Canada (e.g., Deutsch et al., 1995), contributed fundamentally to our present understanding of the cratering process.

Among the well-preserved impact structures on Earth, Popigai is outstanding due to the wealth of data accumulated during 20 years of intense exploration work. The structure is most probably linked to ejecta horizons occurring in marine sequences of Late Eocene age (Langenhorst, 1996). It is not by chance that the Popigai impact structure has been included by UNESCO in the list of the world's geological heritage, and severe efforts are now made for its preservation as well as for saving all the information on the structure that has been collected so far. Popigai possesses a large potential for the study of complicated and poorly understood phenomena in impact cratering, including brecciation, melting and ejection of tremendous amounts of target rocks. The potential of Popigai in future basic cratering research rests on several facts: the large diameter of the crater, its well preservation from erosion, the large continuous outcrops, and finally the numerous, up to $1.5 \mathrm{~km}$ long drill cores totaling up to several tens of $\mathrm{km}$ of impact lithologies.

The discovery of impact diamonds in Popigai rocks underlines that giant impact events produce not only strong morphological and structural imprints on the crust or global perturbations of the geosphere (e.g., Sharpton and Ward, 1990; Dressler et al., 1994) but may initiate formation of economically important mineral deposits (Grieve and Masaitis, 1994). During a long period, the presence of diamonds in the Popigai crater was considered as a state secret, and practically all scientific data on the formation and mode of occur- 
rence of impact diamonds remained locked away. It was only announced recently that the total amount of diamond in the Popigai impactites exceeds the resources in all other diamond provinces in the world. Thus, this impact structure may be regarded as CRATER (or bowl cup in the initial sense of this Greek word) filled with diamonds; which, moreover, were made by heavenly forces. Popigai is a wonderful natural phenomenon of immense scientific value, making it a real national treasure!

\section{Acknowledgments}

The joint German-Canadian-Russian expedition to Popigai IPEX 97 was generously supported by the following organizations: German Science Foundation (DFG-Bonn), National Geographic Society (Washington), Canadian Geological Survey (Ottawa), University of Münster (Germany), Gesellschaft zur Förderung der WWU Münster, Karpinsky Geological Institute (St. Petersburg), and Taymirgeolcom (Norilsk). We have appreciated the professional guidance and help of Oleg Simonov (Norilsk), Mischa Goncharov (Khatanga) and Mischa Naumov (St. Petersburg) in the rough country, as well as the expertise of Boris Ivanov (Moscow) in such various fields as translating, modeling of the cratering process, or cooking.

\section{References}

Alvarez, L. W., Alvarez, W., Asaro, F., and Michel, H. V., 1980, Extraterrestrial cause for the Cretaceous-Tertiary extinction: Science, v. 208, pp. 1095-1108.

Bischoff, A., and Stöffler, D., 1992, Shock metamorphism as a fundamental process in the evolution of planetary bodies: Information from meteorites: European Journal of Mineralogy, v. 4, pp. 707-755.

Cameron, A. G. W., 1997, The origin of the moon and the single impact hypotheses V: Icarus, v. 126, pp. 126-137.

Deutsch, A., and Grieve, R. A. F., 1994, The Sudbury Structure: Constraints on its genesis from Lithoprobe results: Geophysical Research Letters, v. 21, pp. 963-966.

Deutsch, A., Grieve, R. A. F., Avermann, M., Bischoff, L., Brockmeyer, P., Buhl, D., Lakomy, R., Müller-Mohr, V., Ostermann, M., and Stöffler, D., 1995, The Sudbury Structure (Ontario, Canada): a tectonically deformed multi-ring impact basin: Geologische Rundschau, v. 84, pp. 697-709.

Dressler, B. O., Grieve, R. A. F., and Sharpton, V. L., eds, 1994, Large Meteorite impacts and planetary evolution: Geological Society of America Special Paper, v. 293, pp. 348.

von Engelhardt, W., Arndt, J., Fecker, B., and Pankau, H. G., 1995, Suevite breccia from the Ries crater, Germany: Origin, cooling history and devitrification of impact glass: Meteoritics, v. 30, pp. 279-293.

French, B. M., 1998 A handbook of shock-metamorphic effects in terrestrial meteorite impact structures: The Lunar and Planetary Institute, Houston, TX, contribution no. 954, pp. 120.

Gehrels, T., ed., 1994, Hazards Due To Comets And Asteroids: Tucson, AZ \& London, Univ. of Arizona Press, pp. 1300.

Greely, R., 1994, Planetary Landscapes: 2nd ed. New York - London, Chapman \& Hall, pp. 286.

Grieve, R. A. F., 1988, The Haughton impact structure: Summary and synthesis of the HISS project: Meteoritics, v. 23, pp. 249-254.

Grieve, R. A. F., 1994, An impact model of the Sudbury Structure: Proceedings. of the Sudbury-Noril'sk Symposium, Ontario Geological Survey Special Volume 5, pp. 119-132.

Grieve, R. A. F., 1998, Extraterrestrial impact on Earth: the evidence and the consequences, in Grady, M. M. et al., eds, Meteorites: Flux with Time and Impact, Effects: Geological Society of London, Special Publication, v. 140 , pp. $105-131$.

Grieve, R. A. F., and Masaitis, V. L., 1994, The economic potential of terrestrial impact craters: International Geological Review, v. 36, pp. 105-151.

Grieve, R. A. F., and Pesonen, L. J., 1996, Terrestrial impact craters: Their spatial and temporal distribution and impacting bodies: Earth, Moon, and Planets, v. 72, pp. 357-376.

Grieve, R. A. F., Langenhorst, F., and Stöffler, D., 1996, Shock metamorphism of quartz in nature and experiment: II. Significance in geoscience: Meteoritics, v. 31, pp. 6-35.
Langenhorst, F., 1994, Shock experiments on $\alpha$ and $\beta$ quartz: II. X-ray and TEM investigations: Earth and Planetary Science Letters, v. 128, pp. 683698.

Langenhorst, F., 1996, Shocked quartz in Late Eocene impact ejecta from Massignano (Ancona, Italy): Clues to shock conditions and source crater: Geology, v. 24, pp. 487-490.

Langenhorst, F., 1997, Impaktdiamanten als Zeugen des intensiven Bombardements aus dem All: Humboldt-Spektrum, University of Berlin, v. 4, no. 2, pp. 32-37.

Langenhorst, F., and Deutsch, A., 1994, Shock experiments on preheated $\alpha$ and B-quartz: I. Optical and density data: Earth and Planetary Science Letters, v. 125, pp. 407-420.

Langenhorst, F., and Deutsch, A., 1998, Mineralogy of Astroblemes - Terrestrial Impact Craters, in Marfunin, A. S., ed, Advanced Mineralogy, Mineral Matter in Space, Mantle, Ocean Floor, Biosphere, Environmental Management, Jewelry: vol. 3, chapter 1.10., pp. 95-119.

Langenhorst, F., Shafranovsky, G.I., Masaitis, V.L., and Koivisto, M., 1999 Discovery of impact diamonds in a Fennoscandian crater and evidence for their genesis by solid-state transformation: Geology, v. 27, pp.747750 .

Masaitis, V. L., 1994, Impactites from Popigai crater, in Dressler, B. O., Grieve, R. A. F., and Sharpton, V. L., eds, Large meteorite impacts and planetary evolution: Geological Society of America Special Paper, v. 293, pp. 153-162.

Masaitis, V. L., 1998, Popigai crater: Origin and distribution of diamondbearing impactites: Meteoritics and Planetary Science, v. 33, pp. 349 359.

Masaitis, V. L., and Raikhlin, A. I., 1986, The Popigai crater formed by the impact of an ordinary chondrite: Doklady Akademii Nauk SSSR, in Russian, v. 286, pp. 1476-1478.

Masaitis, V. L., and Deutsch, A., 1999, Popigai: Gneiss bombs coated with impact melt - heating in the fireball? (abs): Lunar Planetary Science Conference, v. XXX, no. 1237, Lunar Planetary Institute, Houston, CDROM.

Masaitis, V. L., Futergendler, D. I., and Gnevushev, M. A., 1972, Diamonds in impactites of the Popigay meteorite crater: Zapiski Vsesoyuznogo Mineralogicheskogo Obshchestva, v. 101, in Russian, pp. 108-112.

Masaitis, V. L., Mikhailov, M. V., and Selivanovskaya T. V., 1975, The Popigai meteor crater: Moscow, USSR, Nauka Press, in Russian, pp. 123.

Masaitis, V. L., Danilin, A. I., Mashchak, M. S., Raikhlin, A. I., Selivanovskaya, T. V., and Shadenkov, E. M., 1980, The geology of astroblemes: St. Petersburg USSR Russia, "Nedra” Press, in Russian, pp. 231.

Masaitis, V.L., Shafranovsky, G.I., Ezersky, V.A., and Reshetnyak, N.B., 1990, Impact diamonds from ureilites and impactites: Meteoritica, v. 49, pp. 180-195 (in Russian).

Masaitis, V.L., Shafranovsky, G.I., and Federova, I.G., 1995, The apographitic diamonds from astroblemes Ries and Popigai: Proc. Russ. Min. Soc., v. 4, pp. 12-18.

Masaitis, V. L., et al., 1998, Diamond-bearing impactites of the Popigai astrobleme: St. Petersburg, Russia, VSEGEI press, in Russian, pp. 179.

Masaitis, V.L., Shafranovsky, G.I., Grieve, R.A.F., Langenhorst, F., Peredery, W.V., Therriault, A.M., Balmasov, E.L., and Federova, I.G., 2000, Discovery of impact diamonds in black Onaping suevites, Sudbury structure, Ontario, Canada: Geolocical Society of America Special Paper, p.239.

McSween, H. J., Jr., 1994, What have we learned about Mars from SNC meteorites: Meteoritics, v. 29, pp. 757-779.

Melosh, H. J., 1984, Impact ejection, spallation, and the origin of meteorites: Icarus, v. 59, pp. 234-260.

Melosh, H. J., 1989, Impact cratering A geological process: New York, NY, Oxford Univ Press, pp. 245.

Morgan, J., Warner, M. R., and the Chicxulub Working Group: Brittan, J., Buffler, R., Camargo, A., Christeson, G., Denton, P., Hildebrand, A., Hobbs, R. W., Macintyre, H., Mackenzie, G., Maguire, P., Marin, L., Nakamura, Y., Pilkington, M., Sharpton, V., Snyder, D. B., Suarez, G., and Trejo, A., 1997, Size and morphology of the Chicxulub impact crater: Nature, v. 390, pp. 472-476.

Roddy, D. J., Boyce, J. M., Colton, G. W., and Dial, A. L., Jr., 1975, Meteor crater, Arizona, rim drilling with thickness, structural uplift, diameter, depth, volume, and mass-balance calculations: Proceedings Lunar Science Conference 6th, pp. 2621-2644.

Sharpton, V. L., and Ward, P. D., 1990, Global catastrophes in earth history: an interdisciplinary conference on impacts, volcanism, and mass mortality: Geological Society of America Special Paper, v. 247, pp. 631.

Smit, J., and Hertogen, J., 1980, An extraterrestrial event at the Cretaceous Tertiary boundary: Nature, v. 285, pp. 198-200. 
Stöffler, D., and Langenhorst, F., 1994, Shock metamorphism of quartz in nature and experiment: I. Basic observation and theory: Meteoritics, v. 29 , no. 2, pp.155-181.

Therriault, A. M., Grieve, R. A. F., and Reimold, W. U., 1997, Original size of the Vredefort structure: Implications for the geological evolution of the Witwatersrand Basin: Meteoritcs and Planetary Science, v. 32, pp. 71-77.

\begin{abstract}
Alexander Deutsch obtained a Ph.D. in geology from the University of Vienna, Austria in 1976. He joined the Swiss Federal Institute of Technology at Zurich with a Swiss post-doc fellowship, and specialized in isotopic dating techniques. After moving in 1983 to Münster, Germany, he got involved in dating of lunar samples. He currently serves as director of a post-graduate research school in planetology. Research interests are focussed on all aspects of impact cratering.
\end{abstract}

Victor L. Masaitis was graduated from the Mining Institute, Leningrad in 1950 as engineering geologist. He obtained a Dr. geol.-min. sci. degree during the investigation of East Siberian basalt provinces and kimberlite fields. At the beginning of 1970s he was engaged in the study of geology, petrology and mineralogy of impact structures which were first revealed by him and his colleagues in Russia. Since 1971 he serves as the leader of the Petrology Division of the A.P.Karpinsky All-Russia Geological Research Institute in St.Petersburg. In 1991 he got the Barringer Award from Meteoritical Society for the achievements in the field of impact cratering.
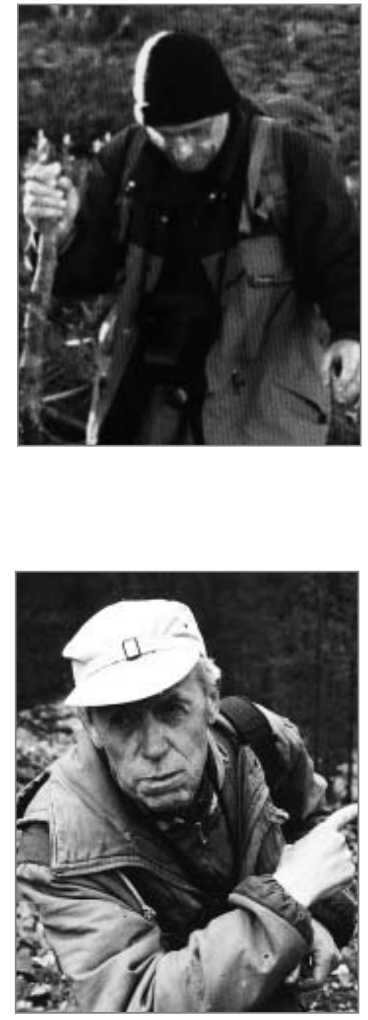

Falko Langenhorst studied mineralogy at the Universities of Gießen and Münster, Germany, where he graduated in 1989. In 1993, he received his Ph.D. degree in planetology from the University of Münster. After a postdoctoral stay at the University of Lille, France, he moved to the Museum of Natural History at the Humboldt University of Berlin and is now at the Bayerisches Geoinstitut, University of Bayreuth (Germany). His personal research involves the experimental simulation and ATEM study of the deformation and transformation behavior of minerals under PT conditions prevailing in impact events and the Earth's mantle.

Richard A.F. Grieve studied geology at the Universities of Aberdeen and Toronto, followed by a research associateship at the University of Oregon. His interest is focussed in planetary geology and the role of impacts on crustal evolution. Apart from three years as a professor at Brown University, his professional career has been as scientist with the Canadian federal government. In 1993, he was awarded the Humboldt Research Prize, which enabled him to spend a year at the Institut für Planetologie, Münster. His scientific accomplishments have been recognised by his election to the Royal Society of Canada. Since 1997, he is Chief Geoscientist of Natural Resources Canada's Earth Sciences Sector.
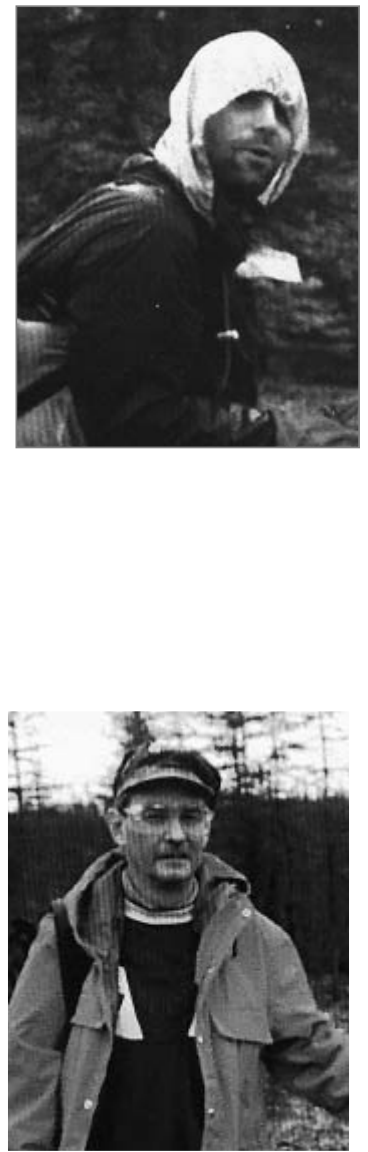